\title{
Association between craniofacial morphological patterns and tooth agenesis- related genes
}

Amanda Silva Rodrigues ${ }^{1 \dagger}$, Ellen Cardoso Teixeira ${ }^{2 \dagger}$, Leonardo Santos Antunes ${ }^{2,3}$, Paulo Nelson-Filho ${ }^{4}$, Arthur Silva Cunha ${ }^{4}$, Simone Carvalho Levy', Mônica Tirre de Souza Araújo ${ }^{5}$, Alice Gomes de Carvalho Ramos ${ }^{6}$, Giuseppe Valduga Cruz ${ }^{7}$, Marjorie Ayumi Omori ${ }^{4}$, Mírian Aiko Nakane Matsumoto ${ }^{4}$, Alexandre Rezende Vieira ${ }^{8}$, Erika Calvano Küchler ${ }^{4,7}$, Guido Artemio Marañón-Vásquez ${ }^{5^{*}}$ and Lívia Azeredo Alves Antunes ${ }^{1,2^{*}}$

\begin{abstract}
Background: The aim of the present study was to assess if genetic polymorphisms in tooth agenesis (TA)-related genes are associated with craniofacial morphological patterns.

Methods: This cross-sectional, multi-center, genetic study evaluated 594 orthodontic Brazilians patients. The presence or absence of TA was determined by analysis of panoramic radiography. The patients were classified according to their skeletal malocclusion and facial growth pattern by means of digital cephalometric analysis. Genomic DNA was extracted from squamous epithelial cells of buccal mucosa and genetic polymorphisms in MSX1 (rs1042484), PAX9 (rs8004560), TGF-a (rs2902345), FGF3 (rs1893047), FGF10 (rs900379), and FGF13 (rs12838463, rs5931572, and rs5974804) were genotyped by polymerase chain reaction using TaqMan chemistry and end-point analysis.

Results: Genotypes ( $p=0.038$ ) and allele ( $p=0.037$ ) distributions for the FGF3 rs1893047 were significantly different according to the skeletal malocclusion. Carrying at least one $\mathrm{G}$ allele increased in more than two times the chance of presenting skeletal class III malocclusion ( $\mathrm{OR}=2.21, \mathrm{Cl} 95 \%=1.14-4.32 ; p=0.017)$. There was no association between another skeletal craniofacial pattern and some polymorphism assessed in the present study.
\end{abstract}

Conclusion: Our results suggest that the genetic polymorphism rs1893047 in FGF3 might contribute to variations in the craniofacial sagittal pattern.

Keywords: Anodontia, Maxillofacial development, Polymorphism, Genetic

\footnotetext{
*Correspondence: guido_amv@hotmail.com; liviaazeredo@gmail.com

${ }^{+}$Amanda Silva Rodrigues and Ellen Cardoso Teixeira contributed equally to

this work.

${ }^{5}$ Department of Pediatric Dentistry and Orthodontics, School of Dentistry,

Federal University of Rio de Janeiro, Rua Prof. Rodolpho Paulo Rocco, 325-

Cidade Universitária, Rio de Janeiro, RJ 21941-617, Brazil

${ }^{1}$ School of Dentistry, Fluminense Federal University, Rua São Paulo 28,

Campus do Valonguinho, Niterói, RJ 24020-150, Brazil

Full list of author information is available at the end of the article
}

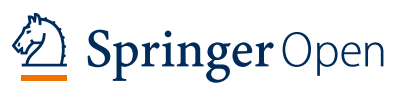

The Author(s). 2020 Open Access This article is licensed under a Creative Commons Attribution 4.0 International License, which permits use, sharing, adaptation, distribution and reproduction in any medium or format, as long as you give appropriate credit to the original author(s) and the source, provide a link to the Creative Commons licence, and indicate if changes were made. The images or other third party material in this article are included in the article's Creative Commons licence, unless indicated otherwise in a credit line to the material. If material is not included in the article's Creative Commons licence and your intended use is not permitted by statutory regulation or exceeds the permitted use, you will need to obtain permission directly from the copyright holder. To view a copy of this licence, visit http://creativecommons.org/licenses/by/4.0/. 


\section{Background}

Tooth agenesis (TA) is the congenital absence of one or more teeth. This condition results from disturbances at early stages of odontogenesis. Several studies have demonstrated that mutations and genetic polymorphisms within specific genes may contribute to the presence of TA; among them are MSX1 [1], PAX9 [1], TGF- $\alpha$ [2] and genes from the $F G F$ family [3, 4].

MSX1 (muscle segment homeobox 1) is expressed during epithelial-mesenchymal interactions that occur at the beginning of tooth formation [5]. Mutations on this gene are related to failures in the development of multiple teeth, preferentially premolars [6]. Msx1 deficient mice showed cleft palate, alveolar bone defects, anomalies in various facial bones, and failure of tooth development [7], suggesting that TA could be genetically related to the development of cranium, maxillary, and mandibular complex [8]. On the other hand, $P A X 9$ (paired box gene 9) is expressed in the neural-crest-derived mesenchyme of the maxillary/mandibular arches and also contributes to tooth and palate formation [9]. Mutation in PAX9 gene was associated with autosomal dominant oligodontia, usually affecting the majority of permanent molars [10]. Pax9 deficient mice presented agenesis of all teeth, cleft palate, and other craniofacial anomalies [5].

TGF- $\alpha$ (transforming growth factor-alpha) is a gene expressed during craniofacial development [11]. Although, mice with $T g f-\alpha$ deficiency did not show tooth anomalies [12], human studies evidenced that genetic polymorphisms in TGF- $\alpha$ contributes to the presence of TA [2]. Regarding the FGF (fibroblast growth factor) signaling, its role in craniofacial development has extensively investigated $[13,14]$. This has an inductive function on craniofacial primordia formation and controls the balance among cell growth, differentiation, and apoptosis [13]. FGF signaling is expressed during tooth development [15] and it was associated with isolated TA $[3,4]$.

Some previous studies have reported an association between TA and craniofacial morphological patterns [16-23], including retrognathic maxilla [18], class III skeletal malocclusion [18, 22], and concave profile [21]. Additionally, our recent study demonstrated that TAassociated GLI2 and GLI3 genes might play a role in the development of skeletal malocclusions [24]. We therefore reaffirm the hypothesis that TA could share a similar genetic background with specific craniofacial morphologies or skeletal malocclusions, and that genetic polymorphisms on additional TA-associated genes may contribute to the establishment of both conditions. In the present study, we aimed to evaluate whether polymorphisms in TA-related MSX1, PAX9, TGF- $\alpha$, FGF3, FGF10, and FGF13 genes contribute to the development of different craniofacial morphological patterns.

\section{Materials and methods}

The protocol of this study was approved by the Research Ethics Committees of the Antônio Pedro University Hospital at the Fluminense Federal University $\left(\mathrm{n}^{\circ}\right.$ 33791314.3.0000.5243), School of dentistry of Ribeirão Preto at the University of São Paulo ( $\mathrm{n}^{\circ}$ 50765715.3.0000.5419), and the Institutional review board committee at the University of Pittsburgh (no. 12080056). An informed consent form was obtained from all participants or legal guardians.

Orthodontic dental records from 766 ethnically heterogeneous Brazilians were assessed for recruitment (from July 2015 to August 2017). Five hundred and ninety-four orthodontic patients (mean age $=23.1 ; 238$ males, 356 females) from private and graduate orthodontic clinics in Rio de Janeiro $(n=325)$, São Paulo $(n=140)$, and Amazonas cities $(n=129)$ were selected following convenience sampling. Location setting and ethnic composition of each city were already described in previous studies $[24,25]$. Patients with one of the following conditions were excluded: previous orthodontic treatment, medical systemic conditions, craniofacial congenital or syndromic anomalies, permanent teeth lost or extracted, and previous facial trauma. Individuals were classified according to the presence/absence of TA, 5.22\% presented agenesis of at least one permanent tooth, excluding third molars [24].

\section{Cephalometric assessment}

Pretreatment lateral cephalometric radiographs of patients were scanned using the HP Scanjet G4050 scanner (L1957A; Hewlett Packard, Washington, USA). The images were imported to the Dolphin ${ }^{\bullet}$ Imaging 11.0 software (Dolphin Imaging and Management Solutions, Chatsworth, CA, USA) and then traced and analyzed by calibrated orthodontists. Ten percent of the radiographs were randomly selected and examined twice to test intra- and inter-examiner reproducibility (4-week interval) using the Intraclass Correlation Coefficient (ICC). ICC for repeated measurements ranged from $0.79-0.87$.

The ANB angle was used to classify the individuals by their sagittal skeletal malocclusion (class $\mathrm{I} 0^{\circ}$ to $4.0^{\circ}$; class II $>4.0^{\circ}$; class III ANB $<0^{\circ}$ ). On the other hand, the NaBa-PtGn angle was used to categorize the subjects by their facial growth pattern (mesofacial $87.0^{\circ}-93.0^{\circ}$, dolichofacial $<87.0^{\circ}$, and brachyfacial $>93.0^{\circ}$ ).

\section{DNA extraction and Genotyping}

Genomic DNA was extracted from saliva samples for molecular analysis according to a previously reported method [26]. Quantification of the concentration and purity of the DNA was determined using a spectrophotometer (Nanodrop 1000; Thermo Scientific, Wilmington, DE, USA). 
Table 1 Studied genetic polymorphisms

\begin{tabular}{|c|c|c|c|c|c|}
\hline Gene & Locus & Reference sequence & Type of alteration & Base change (context sequence) & Global MAF \\
\hline MSX1 & $4 p 16.2$ & rs1042484 & Intron variant & TCC[A/G]ATG & $0.1464 / 733$ \\
\hline PAX9 & $14 q 13.3$ & rs8004560 & Intron variant & $\mathrm{TAA}[\mathbf{A} / \mathrm{G}] \mathrm{TAT}$ & $0.3714 / 1860$ \\
\hline TGFa & $2 \mathrm{p} 13.3$ & rs2902345 & Intron variant & $\mathrm{GGT}[\mathrm{C} / \mathrm{T}] \mathrm{GCC}$ & $0.4022 / 2014$ \\
\hline FGF3 & $11 q 13.3$ & rs1893047 & Intron variant & $\mathrm{CAC}[\mathbf{A} / \mathrm{G}] \mathrm{TGA}$ & $0.4545 / 2276$ \\
\hline FGF10 & $5 p 12$ & rs900379 & Intron variant & $\mathrm{CCT}[\mathrm{C} / \mathrm{T}] \mathrm{ATA}$ & $0.4661 / 2334$ \\
\hline FGF13 & Xq26.3 & rs12838463 & Intron variant & ATC[A/G]TAG & $0.4437 / 1675$ \\
\hline FGF13 & Xq27.1 & rs5931572 & Intron variant & ATT[A/G]TTT & $0.4575 / 1727$ \\
\hline FGF13 & Xq27.1 & rs5974804 & Intron variant & $\mathrm{CAT}[\mathrm{C} / \mathrm{T}] \mathrm{GGT}$ & $0.4967 / 1875$ \\
\hline
\end{tabular}

Source of information: dbSNP from: https://www.ncbi.nlh.nih.gov/snp/, http://genome.uscs.edu/, and https://www.thermofisher.com

Bold: lower frequency allele

Eight genetic polymorphisms, located in intronic regions, were assessed: MSX1 (rs1042484), PAX9 (rs8004560), TGF- $\alpha$ (rs2902345), FGF3 (rs1893047), FGF10 (rs900379), and FGF13 (rs12838463, rs5931572, and rs5974804) (Table 1). The polymorphisms were blindly genotyped by polymerase chain reactions (PCR) using the TaqMan method (ABI Prism 7900HT, Applied Biosystems, Foster City, CA, USA) [27] and end-point analysis. The interpretation of the data was performed using software provided by Applied Biosystems (Foster City, CA, USA) for allelic discrimination.

\section{Statistical analysis}

Statistical analyses were performed on Epi Info 3.5.2 (www.cdc.gov/epiinfo) and Plink (http://zzz.bwh.harvard. edu/plink/), using an established $\alpha$ of 0.05 . Chi-square

Table 2 Genotype and allele distribution between TA and non-TA participants

\begin{tabular}{|c|c|c|c|c|c|c|c|}
\hline \multirow{2}{*}{$\begin{array}{l}\text { Genetic polymorphism } \\
\text { MSX1 rs1042484 }\end{array}$} & \multicolumn{3}{|c|}{ Genotypes, n (\%) } & \multirow[t]{2}{*}{$p$ value } & \multicolumn{2}{|c|}{ Alleles, $n(\%)$} & \multirow[t]{2}{*}{$p$ value } \\
\hline & AA & AG & GG & & A & G & \\
\hline TA & $12(66.7)$ & $3(16.7)$ & $3(16.7)$ & 0.414 & $27(75.0)$ & $9(25.0)$ & 0.475 \\
\hline Non-TA & $239(70.5)$ & $73(21.5)$ & $27(8.0)$ & & $551(81.3)$ & $127(18.7)$ & \\
\hline PAX9 rs8004560 & AA & AG & GG & & A & G & \\
\hline TA & $11(57.9)$ & $6(31.6)$ & $2(10.5)$ & 0.783 & $28(73.7)$ & $10(26.3)$ & 0.740 \\
\hline Non-TA & $214(65)$ & $81(24.6)$ & $34(10.3)$ & & $509(77.4)$ & 149 (22.6) & \\
\hline TGFa1 rs2902345 & $\mathrm{CC}$ & $\mathrm{CT}$ & $\mathrm{TT}$ & & C & $\mathbf{T}$ & \\
\hline TA & $6(23.1)$ & $12(46.2)$ & $8(30.8)$ & 0.495 & $24(46.2)$ & $28(53.8)$ & 0.317 \\
\hline Non-TA & $111(30.0)$ & $180(48.6)$ & 79 (21.4) & & $402(54.3)$ & $338(45.7)$ & \\
\hline FGF3 rs1893047 & AA & AG & GG & & A & G & \\
\hline TA & $17(68)$ & $7(28)$ & $1(4)$ & 0.507 & $41(82.0)$ & $9(18.0)$ & 0.881 \\
\hline Non-TA & $359(74.4)$ & $92(19)$ & $32(6.6)$ & & $810(83.8)$ & $156(16.2)$ & \\
\hline FGF10 rs900379 & $\mathrm{CC}$ & $\mathrm{CT}$ & $\mathrm{TT}$ & & $\mathrm{C}$ & $\mathrm{T}$ & \\
\hline TA & $10(35.7)$ & $11(39.3)$ & $7(25)$ & 0.775 & $24(46.2)$ & $28(53.8)$ & 0.555 \\
\hline Non-TA & $164(29.4)$ & $244(43.8)$ & $149(26.8)$ & & $572(51.3)$ & $542(48.7)$ & \\
\hline FGF13 rs 12838463 & AA & AG & GG & & A & G & \\
\hline TA & 19 (51.4) & $9(24.3)$ & $9(24.3)$ & 0.828 & $47(63.5)$ & $27(36.5)$ & 0.306 \\
\hline Non-TA & $360(46.2)$ & $212(27.2)$ & 207 (26.6) & & $932(59.8)$ & $626(40.2)$ & \\
\hline FGF13 rs5931572 & AA & AG & GG & & A & G & \\
\hline TA & $9(32.1)$ & $10(35.8)$ & $9(32.1)$ & 0.783 & $28(50.0)$ & $28(50.0)$ & 0.340 \\
\hline Non-TA & $170(32.1)$ & $160(30.2)$ & $200(37.7)$ & & $500(47.2)$ & $560(52.8)$ & \\
\hline FGF13 rs5974804 & AA & AG & GG & & A & G & \\
\hline TA & $8(40)$ & $6(30)$ & $6(30)$ & 0.884 & $22(55.0)$ & $18(45.0)$ & 0.520 \\
\hline Non-TA & $194(43.5)$ & $112(25.10)$ & $140(31.4)$ & & $500(56.1)$ & $392(43.9)$ & \\
\hline
\end{tabular}

*Statistical significance $(p \leq 0.05)$. For genetic polymorphisms in FGF13, analyses were adjusted by the gender 
test (with Yates' correction for continuity, when necessary) or Fisher's exact test were performed to determine association between allele/genotype frequencies and the craniofacial phenotypes assessed. For the polymorphisms located in the chromosome $\mathrm{X}$ (polymorphisms in FGF13), an analysis adjusted by the gender was performed. Due to the multiple comparisons made, a Bonferroni correction was applied for each evaluated outcome (corrected $p$ value $=0.00625 ; 0.05 / 8$ genetic polymorphisms assessed). Genotype/phenotype associations were also tested in the dominant and recessive models. Chi-square test was also used to evaluate the Hardy-Weinberg equilibrium.

\section{Results}

The distribution of genotypes followed Hardy-Weinberg equilibrium (data not shown). Information regarding the association between skeletal malocclusion and TA was reported in a previous published paper [24]; individuals presenting class II skeletal malocclusion showed lower frequency of TA. There was no significant association between genotype/allele distributions and the presence of TA for any polymorphism assessed in the present study $(p>0.05)$ (Table 2$)$.

Genotype $(p=0.038)$ and allele $(p=0.037)$ distributions for the FGF3 rs1893047 were significantly different between class III and class I individuals (Table 3). Analysis

Table 3 Genotype and allele distribution among class I, class II and class III skeletal malocclusions

\begin{tabular}{|c|c|c|c|c|c|c|c|}
\hline \multirow{2}{*}{$\begin{array}{l}\text { Genetic polymorphism } \\
\text { MSX1 rs1042484 }\end{array}$} & \multicolumn{3}{|c|}{ Genotypes, $n$ (\%) } & \multirow[t]{2}{*}{$p$ value } & \multicolumn{2}{|c|}{ Alleles, $n$ (\%) } & \multirow[t]{2}{*}{$p$ value } \\
\hline & $A A$ & AG & GG & & $A$ & G & \\
\hline Class I & $118(69.8)$ & $38(22.5)$ & $13(7.7)$ & Reference & $274(81.1)$ & 64 (18.9) & Reference \\
\hline Class II & $106(71.1)$ & $29(19.5)$ & $14(9.4)$ & 0.730 & $241(80.9)$ & $57(19.1)$ & 0.999 \\
\hline Class III & $26(70.3)$ & $8(21.6)$ & $3(8.1)$ & 0.990 & $60(81.1)$ & $14(18.9)$ & 0.863 \\
\hline PAX9 rs8004560 & AA & AG & GG & & A & G & \\
\hline Class I & $91(62.3)$ & $35(24.0)$ & $20(13.7)$ & Reference & $217(74.3)$ & $75(25.7)$ & Reference \\
\hline Class II & $100(67.1)$ & $39(26.2)$ & $10(6.7)$ & 0.140 & $239(80.2)$ & 59 (19.8) & 0.108 \\
\hline Class III & $25(62.5)$ & $10(25.0)$ & $5(12.5)$ & 0.975 & $60(75.0)$ & $20(25.0)$ & 0.999 \\
\hline TGFa1 rs2902345 & $\mathrm{CC}$ & $\mathrm{CT}$ & TT & & $\mathrm{C}$ & $\mathrm{T}$ & \\
\hline Class I & $51(28.5)$ & $89(49.7)$ & 39 (21.8) & Reference & $191(53.4)$ & $167(46.6)$ & Reference \\
\hline Class II & $46(28.8)$ & $77(48.1)$ & $37(23.1)$ & 0.947 & $169(52.8)$ & $151(47.2)$ & 0.999 \\
\hline Class III & $16(37.2)$ & $22(51.2)$ & $5(11.6)$ & 0.261 & $54(62.8)$ & $32(37.2)$ & 0.144 \\
\hline FGF3 rs1893047 & AA & AG & GG & & A & G & \\
\hline Class I & $157(76.6)$ & $36(17.6)$ & $12(5.9)$ & Reference & $350(85.4)$ & $60(14.6)$ & Reference \\
\hline Class II & $165(75.3)$ & 39 (17.8) & $15(6.8)$ & 0.932 & $369(84.2)$ & 69 (15.8) & 0.964 \\
\hline Class III & $28(59.6)$ & $16(34.0)$ & $3(6.4)$ & $0.038^{*}$ & $72(76.6)$ & $22(23.4)$ & $0.037^{*}$ \\
\hline FGF10 rs900379 & $\mathrm{CC}$ & $\mathrm{CT}$ & TT & & C & $\mathrm{T}$ & \\
\hline Class I & $70(29.8)$ & $107(45.5)$ & $58(24.7)$ & Reference & $247(52.6)$ & $223(47.4)$ & Reference \\
\hline Class II & $72(30.5)$ & $115(48.7)$ & 49 (20.8) & 0.585 & $259(54.9)$ & $213(45.1)$ & 0.509 \\
\hline Class III & 19 (33.3) & $20(35.1)$ & 18 (31.6) & 0.336 & $58(50.9)$ & $56(49.1)$ & 0.103 \\
\hline FGF13 rs12838463 & AA & AG & GG & & A & G & \\
\hline Class I & $110(47.8)$ & $65(28.3)$ & $55(23.9)$ & Reference & $285(62.0)$ & $175(38.0)$ & Reference \\
\hline Class II & $112(46.9)$ & $60(25.1)$ & $67(28.0)$ & 0.541 & $284(59.4)$ & $194(40.6)$ & 0.765 \\
\hline Class III & $29(50.9)$ & $14(24.6)$ & $14(24.6)$ & 0.850 & $72(63.2)$ & $42(36.8)$ & 0.876 \\
\hline FGF13 rs5931572 & AA & AG & GG & & A & G & \\
\hline Class I & $72(32.6)$ & $63(28.5)$ & $86(38.9)$ & Reference & $207(46.8)$ & $235(53.2)$ & Reference \\
\hline Class II & $67(29.5)$ & 65 (28.6) & 95 (41.9) & 0.749 & 199 (43.8) & $255(56.2)$ & 0.823 \\
\hline Class III & $16(30.8)$ & $15(28.8)$ & $21(40.4)$ & 0.966 & $47(45.2)$ & $57(54.8)$ & 0.091 \\
\hline FGF13 rs5974804 & AA & AG & GG & & A & G & \\
\hline Class I & $83(42.1)$ & $50(25.4)$ & $64(32.5)$ & Reference & $216(54.8)$ & $178(45.2)$ & Reference \\
\hline Class II & $80(44.7)$ & $48(26.8)$ & $51(28.5)$ & 0.897 & $208(58.1)$ & $150(41.9)$ & 0.820 \\
\hline Class III & $22(46.8)$ & $9(19.1)$ & $16(34.0)$ & 0.678 & $53(56.4)$ & 41 (43.6) & 0.784 \\
\hline
\end{tabular}

*Statistical significance $(p \leq 0.05)$. For genetic polymorphisms in FGF13, analyses were adjusted by the gender. 
in the dominant model (AG + GG vs. AA) demonstrated that carrying at least one $G$ allele increased in more than two times the chance of presenting skeletal class III malocclusion $(\mathrm{OR}=2.21,95 \% \mathrm{CI}=1.14-4.32 ; p=0.017)$. There was no association between the facial growth pattern and any polymorphism assessed in the present study $(p>0.05)$ (Table 4). No reported associations remained significant after the Bonferroni correction.

\section{Discussion}

Many human and animal studies support that dental anomalies, mainly TA, and craniofacial alterations could share a common genetic background [7, 9, 12-24, 28, 29].
The identification of genes contributing to the establishment of craniofacial morphological patterns can impact the clinical practice, allowing genetic counseling of individuals carrying specific variants and their families, and to work on preventive strategies. To the best of our knowledge, this is the first report investigating the association between genetic polymorphisms in TA-related genes$M S X 1, P A X 9, T G F-\alpha$, and FGF signaling-and craniofacial morphological patterns (associated or not with TA).

$M S X 1, P A X 9, T G F-\alpha$, and FGF genes are responsible for the patterning of tooth development $[7,9,15,30]$. Previous studies performed in Brazilian families (trio designs) and case-controls studies demonstrated that TA

Table 4 Genotype and allele distribution among mesofacial, dolichofacial, and brachyfacial growth patterns

\begin{tabular}{|c|c|c|c|c|c|c|c|}
\hline \multirow{2}{*}{$\frac{\text { Genetic polymorphism }}{\text { MSX1 rs1042484 }}$} & \multicolumn{3}{|c|}{ Genotypes, n (\%) } & \multirow[t]{2}{*}{$p$ value } & \multicolumn{2}{|c|}{ Alleles, $n$ (\%) } & \multirow[t]{2}{*}{$p$ value } \\
\hline & AA & AG & GG & & A & A & \\
\hline Mesofacial & 119 (69.6) & $35(20.5)$ & $17(9.9)$ & Reference & $273(79.8)$ & $69(20.2)$ & Reference \\
\hline Dolichofacial & 77 (70.6) & $22(20.2)$ & $10(9.2)$ & 0.975 & $176(80.7)$ & $42(19.3)$ & 0.888 \\
\hline Brachyfacial & $54(72.0)$ & $18(24.0)$ & $3(4.0)$ & 0.271 & $126(84)$ & $24(16)$ & 0.335 \\
\hline$P A X 9$ rs 8004560 & AA & AG & GG & & A & G & \\
\hline Mesofacial & $103(66.5)$ & $37(23.9)$ & $15(9.7)$ & Reference & $243(78.4)$ & $67(21.6)$ & Reference \\
\hline Dolichofacial & $70(63.1)$ & $28(25.2)$ & $13(11.7)$ & 0.811 & $168(75.7)$ & $54(24.3)$ & 0.527 \\
\hline Brachyfacial & $43(62.3)$ & $19(27.5)$ & $7(10.1)$ & 0.823 & $105(76.1)$ & $33(23.9)$ & 0.680 \\
\hline TGFa1 rs2902345 & CC & CT & TT & & C & $\mathbf{T}$ & \\
\hline Mesofacial & $51(27.4)$ & $95(51.1)$ & $40(21.5)$ & Reference & $197(53.0)$ & $175(47)$ & Reference \\
\hline Dolichofacial & $35(30.2)$ & $55(47.4)$ & $26(22.4)$ & 0.815 & $125(53.9)$ & $107(46.1)$ & 0.888 \\
\hline Brachyfacial & $27(33.8)$ & $38(47.5)$ & $15(18.8)$ & 0.574 & $92(57.5)$ & $68(42.5)$ & 0.383 \\
\hline FGF3 rs1893047 & AA & AG & GG & & A & G & \\
\hline Mesofacial & $166(75.1)$ & $39(17.6)$ & $16(7.2)$ & Reference & $371(83.9)$ & $71(16.1)$ & Reference \\
\hline Dolichofacial & $111(75.5)$ & $28(19.0)$ & $8(5.4)$ & 0.765 & $250(85.0)$ & $44(15.0)$ & 0.865 \\
\hline Brachyfacial & $73(70.9)$ & $24(23.3)$ & $6(5.8)$ & 0.464 & $170(82.5)$ & $36(17.5)$ & 0.886 \\
\hline FGF10 rs900379 & CC & $\mathrm{CT}$ & TT & & $C$ & $\mathbf{T}$ & \\
\hline Mesofacial & 78 (31.0) & $118(46.8)$ & $56(22.2)$ & Reference & $274(54.4)$ & $230(45.6)$ & Reference \\
\hline Dolichofacial & $49(30.2)$ & $73(45.1)$ & $40(24.7)$ & 0.873 & $171(52.8)$ & $153(47.2)$ & 0.871 \\
\hline Brachyfacial & $34(29.8)$ & $51(44.7)$ & $29(25.4)$ & 0.658 & $119(52.2)$ & $109(47.8)$ & 0.798 \\
\hline \multicolumn{8}{|l|}{ FGF13 rs12838463 } \\
\hline Mesofacial & $116(47.0)$ & $63(25.5)$ & $68(27.5)$ & Reference & $295(59.7)$ & 199 (40.3) & Reference \\
\hline Dolichofacial & 79 (47.6) & $43(25.9)$ & $44(26.5)$ & 0.911 & $201(60.5)$ & $131(39.5)$ & 0.981 \\
\hline Brachyfacial & $56(49.6)$ & $33(29.2)$ & $24(21.2)$ & 0.624 & $145(64.2)$ & $81(35.8)$ & 0.678 \\
\hline FGF13 rs5931572 & AA & AG & GG & & A & G & \\
\hline Mesofacial & $70(29.2)$ & $69(28.8)$ & $101(42.1)$ & Reference & $209(43.5)$ & $271(56.5)$ & Reference \\
\hline Dolichofacial & $54(35.3)$ & $40(26.1)$ & 59 (38.6) & 0.443 & $148(48.4)$ & $158(51.6)$ & 0.746 \\
\hline Brachyfacial & $31(29.0)$ & $34(31.8)$ & $42(39.3)$ & 0.830 & $96(44.9)$ & $118(55.1)$ & 0.104 \\
\hline FGF13 rs5974804 & AA & AG & GG & & A & $\mathbf{G}$ & \\
\hline Mesofacial & $84(42.6)$ & $49(24.9)$ & $64(32.5)$ & Reference & $217(55.1)$ & $177(44.9)$ & Reference \\
\hline Dolichofacial & $60(46.9)$ & $33(25.8)$ & $35(27.3)$ & 0.602 & $153(59.8)$ & $103(40.2)$ & 0.139 \\
\hline Brachyfacial & $41(41.8)$ & $25(25.5)$ & 32 (32.7) & 0.989 & 107 (54.6) & $89(45.4)$ & 0.912 \\
\hline
\end{tabular}

*Statistical significance $(p \leq 0.05)$. For genetic polymorphisms in FGF13, analyses were adjusted by the gender. 
was associated with MSX1, PAX9, TGF- $\alpha$ [2], FGF3 [2], and FGF10 [3]. In the present study, none of the studied genetic polymorphisms were associated with TA. These results should be carefully evaluated, because they may be due to methodological limitations of the present study (small sample size of individuals with TA, sampling limitations, failure rate of genotyping procedures), which could have led to type II error.

On the other hand, it has been demonstrated that Msxi deficient mice show shortened mandibles, anteroposterior deficiency in the middle third of the face, and subtle abnormalities in overall head size and cranial shape [7]. Also, Pax9 deficient mice present agenesis of all teeth, cleft palate, and other craniofacial anomalies [5]. TGF- $\alpha$ is a gene expressed during craniofacial development [11]; mice with $T g f-\alpha$ deficiency presented eye and hair anomalies [12]. Despite the above-described roles of these genes, the genetic polymorphisms studied within MSX1, PAX9, and $T G F-\alpha$ were not associated with none of the craniofacial morphological patterns assessed (skeletal malocclusions and facial type). Considering that previous studies support that genetic polymorphisms and mutations in these genes did show association with craniofacial patterns $[2,6,10$, 31-33], it is possible that other genetic variants within these genes are involved in the etiology of the craniofacial phenotypes in this population.

Fgf signaling is involved in various regulatory processes during embryogenesis as well as in the adult organism [34, 35]. This signal pathway has key roles in suture and synchondrosis regulation; mutations in FGF receptors cause craniosynostosis, which is the premature suture fusion $[36,37]$. On the other hand, Fgf signal participates in multiple stages of palatogenesis, from palatal shelf elevation to the completion of fusion [38]. Therefore, disturbances in Fgf-related pathways are possible mechanisms of palatal cleft. Based on the above, it is clear that $F G F$ is considered a candidate gene for study in relation to variations in the morphology of the craniofacial skeleton. In our study, carrying at least one $G$ allele in the polymorphism rs1893047 within FGF3 increased the chance of presenting skeletal class III malocclusion. Considering that multiple members of this gene family are expressed mainly during midfacial region development [39], among them FGF3, we hypothesize that variations on this gene could contribute to the development of class III due to maxillary growth deficiency. A stratified analysis according to the maxilla contribution on class III was not possible due to the low prevalence of class III individuals in our sample, and the consequent significant reduction that would have existed in the power of the analyses.

It has been shown that Fgf3 is expressed during development and outgrowth of the facial primordia and branchial arches [39-41], and during odontogenesis [42, 43].
Additionally, this gene has been associated with oral cleft [31] and TA [2], suggesting that FGF3 plays a role in both craniofacial phenotypes. Our data must be carefully interpreted since significant results could be due to chance. Statistical significance did not persist for the reported associations after the Bonferroni correction.

Briefly, the knowledge regarding the role of genetic polymorphisms on craniofacial development offers the possibility of establishing new strategies to prevent these disorders. Further investigations with other genetic polymorphisms in these genes are necessary to confirm our results.

\section{Conclusion}

Our result suggests that genetic polymorphism rs1893047 in FGF3 might contribute to variations in the craniofacial sagittal pattern, specifically to the establishment of the Class III skeletal malocclusion.

\begin{abstract}
Abbreviations
TA: Tooth agenesis; ICC: Intraclass correlation coefficient; PCR: Polymerase chain reaction
\end{abstract}

\section{Acknowledgements}

Not applicable.

\section{Authors' contributions}

ASR: conception and design of the study, acquisition of data, analysis and interpretation of data, drafting the article, and final approval of the version to be submitted. ECT: acquisition of data, analysis and interpretation of data, revising the article for important intellectual content, and final approval of the version to be submitted. LSA: conception and design of the study, revising the article for important intellectual content, and final approval of the version to be submitted. PNF: analysis and interpretation of data, revising the article for important intellectual content, and final approval of the version to be submitted. AC: acquisition of data, revising the article for important intellectual content, and final approval of the version to be submitted. SCL: acquisition of data, revising the article for important intellectual content, and final approval of the version to be submitted. MTSA: analysis and interpretation of data, revising the article for important intellectual content, and final approval of the version to be submitted. AGCR: acquisition of data, revising the article for important intellectual content, and final approval of the version to be submitted. GVC: analysis and interpretation of data, revising the article for important intellectual content, and final approval of the version to be submitted. MAO: acquisition of data, revising the article for important intellectual content, and final approval of the version to be submitted. MANM: analysis and interpretation of data, revising the article for important intellectual content, and final approval of the version to be submitted. ARV: analysis and interpretation of data, revising the article for important intellectual content, and final approval of the version to be submitted. ECK: conception and design of the study, analysis and interpretation of data, drafting the article, and final approval of the version to be submitted. GAMV: acquisition of data, analysis and interpretation of data, drafting the article, and final approval of the version to be submitted. LAAA: conception and design of the study, analysis and interpretation of data, revising the article for important intellectual content, and final approval of the version to be submitted.

\section{Funding}

This work was supported by the São Paulo Research Foundation (FAPESP) (2015/06866-5, 2016/08149-1).

Availability of data and materials

The data will be made available upon request to the authors. 


\section{Ethics approval and consent to participate}

The protocol of this study was approved by the Research Ethics Committees of the Antônio Pedro University Hospital at the Fluminense Federal University (no. 33791314.3.0000.5243), School of dentistry of Ribeirão Preto at the University of São Paulo (no. 50765715.3.0000.5419), and the Institutional review board committee at the University of Pittsburgh (no. 12080056). An informed consent form was obtained from all participants or legal guardians.

\section{Consent for publication}

Not applicable.

\section{Competing interests}

The authors declare that they have no competing interests.

\section{Author details}

${ }^{1}$ School of Dentistry, Fluminense Federal University, Rua São Paulo 28, Campus do Valonguinho, Niterói, RJ 24020-150, Brazil. '2School of Dentistry, Fluminense Federal University, Rua Doutor Sílvio Henrique Braune 22, Niterói, Nova Friburgo, RJ 28625-650, Brazil. ${ }^{3}$ Clinical Research Unit, Fluminense Federal University, Rua Mario Santos Braga 30, Niterói, RJ 24020-140, Brazil. ${ }^{4}$ Department of Pediatric Dentistry, School of Dentistry of Ribeirão Preto, University of São Paulo, Avenida do Café s/n-Campus da USP, Ribeirão Preto, SP 14040-904, Brazil. ${ }^{5}$ Department of Pediatric Dentistry and Orthodontics, School of Dentistry, Federal University of Rio de Janeiro, Rua Prof. Rodolpho Paulo Rocco, 325-Cidade Universitária, Rio de Janeiro, RJ 21941-617, Brazil. ${ }^{6}$ Amazonian Education Institute, Rua Maceió 861, Adrianópolis, Manaus, AM 69057-010, Brazil. 'Department of Oral and Maxillofacial Surgery, Positivo University, Rua Professor Pedro Viriato Parigot de Souza 5300-Campo Comprido, Curitiba, PR 81200-452, Brazil. ${ }^{8}$ Department of Oral Biology, School of Dental Medicine, University of Pittsburgh, 412 Salk Pavilion, 335 Sutherland Street, Pittsburgh, PA 15261, USA.

\section{Received: 30 December 2019 Accepted: 12 March 2020}

\section{Published online: 06 April 2020}

\section{References}

1. Paixão-Côrtes VR, Braga T, Salzano FM, Mundstock K, Mundstock CA Bortolini MC. PAX9 and MSX1 transcription factor genes in non-syndromic tooth agenesis. Arch Oral Biol. 2011;56:337-44.

2. Vieira AR, Meira R, Modesto A, Murray JC. MSX1, PAX9, and TGFA contribute to tooth agenesis in humans. J Dent Res. 2004;83:723-7.

3. Küchler EC, Lips A, Tannure PN, Ho B, Costa MC, Granjeiro JM, et al. Tooth agenesis association with self-reported family history of cancer. J Dent Res. 2013;92:149-55.

4. Vieira AR, D'Souza RN, Mues G, Deeley K, Hsin HY, Küchler EC, et al. Candidate gene studies in hypodontia suggest role for FGF3. Eur Arch Paediatr Dent. 2013;14:405-10.

5. Peters H, Neubüser A, Kratochwil K, Balling R. PAX9- deficient mice lack pharyngeal pouch derivatives and teeth and exhibit craniofacial and limb abnormalities. Genes Dev. 1998;12:2735-47.

6. Vieira AR. Oral clefts and syndromic forms of tooth agenesis as models for genetics of isolated tooth agenesis. J Dent Res. 2003;82:162-5.

7. Satokata I, Maas R. Msx1 deficient mice exhibit cleft palate and abnormalities of craniofacial and tooth development. Nat Genet. 1994;6: 348-56

8. Endo T, Ozoe R, Yoshino S, Shimooka S. Hypodontia patterns and variations in craniofacial morphology in Japanese orthodontic patients. Angle Orthod. 2006:76:996-1003.

9. Peters H, Balling R. Teeth: where and how to make them. Trends Genet. 1999:15:59-65.

10. Stockton DW, Das P, Goldenberg M, D'Souza RN, Patel PI. Mutation of PAX 9 is associated with oligodontia. Nat Genet. 2000;24:18-9.

11. Dixon MJ, Garner J, Ferguson MWJ. Immunolocalization of epidermal growth factor (EGF), EGF receptor and transforming growth factor alpha (TGF) during murine palatogenesis in vivo and in vitro. Anat Embryol. 1991;184:83-91.

12. Mann GB, Fowler KJ, Gabriel A, Nice EC, Williams RL, Dunn AR. Mice with a null mutation of the TGF gene have abnormal skin architecture, wavy hair, and curly whiskers and often develop corneal inflammation. Cell. 1993;73: 249-61.
13. Ornitz DM, Marie PJ. FGF signaling pathways in endochondral and intramembranous bone development and human genetic disease. Genes Dev. 2002;16:1446-65.

14. Xiong X, Li S, Cai Y. Chen F Targeted sequencing in FGF/FGFR genes and association analysis of variants for mandibular prognathism. Medicine. 2017:96:e7240

15. Du W, Du W, Yu H. The Role of fibroblast growth factors in tooth development and incisor renewal. Stem Cells Int. 2018;2018:7549160.

16. Øgaard B, Krogstad O. Craniofacial structure and soft tissue profile in patients with severe hypodontia. Am J Orthod Dentofacial Orthop. 1995; 108:472-7.

17. Yüksel S, Üçem T. The effect of tooth agenesis on dentofacial structures. Eur J Orthod. 1997:19:71-8.

18. Chan DWS, Samman N, McMillan AS. Craniofacial profile in Southern Chinese with hypodontia. Eur J Orthod. 2009:31:300-5.

19. Sánchez MJ, Vicente A, Bravo LA. Third molar agenesis and craniofacial morphology. Angle Orthod. 2009;79:473-8.

20. Pinho T, Pollmann C, Calheiros-Lobo MJ, Sousa A, Lemos C. Craniofacial repercussions in maxillary lateral incisors agenesis. Int Orthod. 2011:9:274-85.

21. Gungor AY, Turkkahraman H. Effects of severity and location of nonsyndromic hypodontia on craniofacial morphology. Angle Orthod. 2013; 83:584-90.

22. Bajraktarova Miševska C, Kanurkova L, Bajraktarova Valjakova E, Georgieva S, Bajraktarova B, Georgiev Z, et al. Craniofacial morphology in individuals with increasing severity of hypodontia. South Eur J Orthod Dentofac Res. 2016;3:11-6.

23. Bassiouny DS, Afify AR, Baeshen HA, Birkhed D, Zawawi KH. Prevalence of maxillary lateral incisor agenesis and associated skeletal characteristics in an orthodontic patient population. Acta Odontol Scand. 2016;74:456-9.

24. Marañón-Vásquez GA, Dantas B, Kirschneck C, Arid J, Cunha A, Ramos AGC, et al. Tooth agenesis-related GLI2 and GLI3 genes may contribute to craniofacial skeletal morphology in humans. Arch Oral Biol. 2019;103:12-8.

25. Cunha A, Nelson-Filho P, Marañón-Vásquez GA, Ramos AGC, Dantas B Sebastiani AM, et al. Genetic variants in ACTN3 and MYO1H are associated with sagittal and vertical craniofacial skeletal patterns. Arch Oral Biol. 2019; 97:85-90.

26. Küchler EC, Tannure PN, Falagan-Lotsch P, Lopes TS, Granjeiro JM, Amorim LM. Buccal cells DNA extraction to obtain high quality human genomic DNA suitable for polymorphism genotyping by PCR-RFLP and Real-Time PCR. J Appl Oral Sci. 2012;20:467-71.

27. Ranade K, Chang MS, Ting CT, Pei D, Hsiao CF, Olivier M, et al. High-trough put genotyping with single nucleotide polymorphisms. Genome Res. 2001; 11:1262-8.

28. Vieira AR, Orioli IM. Candidate genes for nonsyndromic cleft lip and palate. ASDC J Dent Child. 2001;68:272-9.

29. Küchler EC, da Motta LG, Vieira AR, Granjeiro JM. Side of dental anomalies and taurodontism as potential clinical markers for cleft subphenotypes. Cleft Palate Craniofac J. 2011:48:103-8.

30. Mackenzie A, Ferguson MWJ, Sharpe PT. Expression patterns of the homeobox gene, hox-8, in the mouse embryo suggest a role in specifying tooth initiation and shape. Development. 1992:115:403-20.

31. Küchler EC, Sabóia TM, Vieira TC, Lips A, Tannure PN, Deeley K, et al. Studies of genes involved in craniofacial development and tumorigenesis: FGF3 contributes to isolated oral clefts and may interact with PAX9. Acta Odontol Scand. 2014;72:1070-8.

32. Feng C, Zhang E, Duan W, Xu Z, Zhang Y, Lu L. Association between polymorphism of TGFA Taq I and cleft lip and/or palate: a meta-analysis. BMC Oral Health. 2014;14:88

33. Phan M, Conte F, Khandelwal KD, Ockeloen CW, Bartzela T, Kleefstra T, et al. Tooth agenesis and orofacial clefting: genetic brothers in arms? Hum Genet 2016;135:1299-327.

34. Nie X, Luukko K, Kettunen P. FGF signalling in craniofacial development and developmental disorders. Oral Dis. 2006;12:102-11.

35. Moosa S, Wollnik B. Altered FGF signalling in congenital craniofacial and skeletal disorders. Semin Cell Dev Biol. 2016;53:115-25.

36. Wilkie AO. Craniosynostosis: genes and mechanisms. Hum Mol Genet. 1997;6:1647-56

37. Hatch NE. FGF signaling in craniofacial biological control and pathologica craniofacial development. Crit Rev Eukaryot Gene Expr. 2010;20:295-311.

38. Britto JA, Evans RD, Hayward RD, Jones BM. Toward pathogenesis of Apert cleft palate: FGF, FGFR, and TGF beta genes are differentially expressed in 
sequential stages of human palatal shelf fusion. Cleft Palate Craniofac J. 2002;39:332-40.

39. Bachler M, Neubuser A. Expression of members of the Fgf family and their receptors during midfacial development. Mech Dev. 2001;100:313-6.

40. Walshe J, Mason I. Fgf signalling is required for formation of cartilage in the head. Dev Biol. 2003;264:522-36.

41. Crump JG, Maves L, Lawson ND, Weinstein BM, Kimmel CB. An essential role for Fgfs in endodermal pouch formation influences later craniofacial skeletal patterning. Development. 2004;131:5703-16.

42. Kettunen P, Laurikkala J, Itaranta P, Vainio S, Itoh N, Thesleff I. Associations of FGF-3 and FGF-10 with signaling networks regulating tooth morphogenesis. Dev Dyn. 2000;219:322-32.

43. Jernvall J, Thesleff I. Reiterative signaling and patterning during mammalian tooth morphogenesis. Mech Dev. 2000;92:19-29.

\section{Publisher's Note}

Springer Nature remains neutral with regard to jurisdictional claims in published maps and institutional affiliations.

\section{Submit your manuscript to a SpringerOpen ${ }^{\circ}$ journal and benefit from:}

- Convenient online submission

- Rigorous peer review

- Open access: articles freely available online

- High visibility within the field

- Retaining the copyright to your article

Submit your next manuscript at $\boldsymbol{\nabla}$ springeropen.com 